\title{
The influence of turbulence on morphological variability of Daphnia galeata in Lake Baikal
}

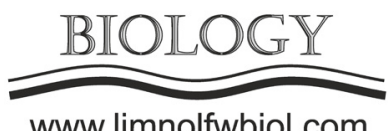

\author{
Pitulko S.I.
}

Limnological Institute of the Siberian Branch of the Russian Academy of Sciences, Irkutsk

\begin{abstract}
Morphological variability resulting from water movement (turbulence) was studied. Currents of different origin and intensity resulting in changes of morphological traits (body size, head height, tail spine length) in Daphnia galeata are observed in pelagic zone and bays of Lake Baikal. Under the conditions of rapid currents, the mature daphnia develop a high helmet, a long tail spine, there are also some changes in ratio of these traits to the body length. Juvenile crustaceans manifest the least pronounced reaction. Besides, combination of predation and turbulence factors result in an intensive development of protective features.
\end{abstract}

Keywords: Lake Baikal, Daphnia galeata, turbulence, turbulence distribution, morphological variability, predation influence, cyclomorphosis.

Daphnia possess variability resulting from different environmental factors: food amount, temperature, turbulence, competition and impact of predators (both vertebrates and invertebrates). The turbulence is formed by water movement of different origin (due to wind, drainage, interaction between water layers of different temperature or density, moving organisms) (Kiselev, 1969; Tollrian and Laforsh, 2006). In summer, at optimal temperatures, the turbulence results in the development of morphological features necessary for swimming (swimming antennae) and for movement direction (tail spine, helmet, carinae). Strong turbulence may cause prevent food flow to food consumers, decreases remote location of a prey by a predator, depresses food behaviour and increases use of metabolic energy (Baranyai et al., 2012).

During open water period, permanent currents in Lake Baikal are formed mainly by wind impact. The velocity of near-surface wind currents is ca. $1.4 \mathrm{~m} / \mathrm{s}$ and promotes considerable passive migrations and panmixis of planktonic organisms within each of lake basins (Verbolov, 1977; Shimaraev and Troitskaya, 2005). Low turbulence levels in Lake Baikal occur in the bays where there is much food, water temperatures are high, and there is such a predator as Leptodora. In open pelagic zone and in near-shore shallow waters, we can observe high currents velocity, small food amount and low temperatures. In Chivyrkuy and Barguzin Bays, average currents velocity is $1 \mathrm{~m} / \mathrm{s}$, in South and North Baikal, mouthes of Barguzin and Chivyrkuy Bays - 2 $\mathrm{m} / \mathrm{s}$, South Baikal $-2.5 \mathrm{~m} / \mathrm{s}$, in Central Baikal and Selenga shallow waters $-3 \mathrm{~m} / \mathrm{s}$.
Methods and placement of sampling points, the number of samples, the number of Daphnia in each sample, and statistical processing are described in the article (Pitul'ko, 2019). The studied retrievals are grouped by dominant current velocities in surface water layer. The first group includes all the retrievals, the second one - only without a predator, the third one - with a predator. The influence of other factors was minimized by formation of maximally homogenous data by environmental factors.

In the whole data set, mature and premature crustaceans $D$. galeata have considerably longer bodies at low turbulence than at high one $(\mathrm{P}<0.05$ and $\mathrm{P}<0,001$, respectively). Under the conditions without a predator, turbulence does not cause any considerable influence on body size neither adult nor juvenile crustaceans. When a predator is available, adult females have for sure larger bodies size at high turbulence $(P<0.05)$. Premature crustaceans in the retrievals without a predator have considerably larger bodies size at low turbulence level $(\mathrm{P}<0.05)$ than at high one. When a predator is available, premature and juvenile crustaceans have considerably smaller bodies length at high turbulence $(\mathrm{P}<0.001$ and $\mathrm{P}<0.001$, respectively). Juvenile crustaceans in the whole data set have smaller bodies size at high turbulence than at low one $(\mathrm{P}<0.001)$.

According to all data available, adult and premature crustaceans have considerably higher helmets at low turbulence $(\mathrm{P}<0.001)$. Under the conditions without a predator, turbulence impact on helmet height in mature and premature crustaceans is 
not found. Under the conditions with a predator, the crustaceans of all age groups have considerable larger helmets at low currents velocity than at high one $(\mathrm{P}<$ 0.001). Juvenile crustaceans from the whole data set have for sure lower helmets at high turbulence. In the retrievals without a predator, juvenile crustaceans have considerably higher helmets at high turbulence that at low one $(\mathrm{P}<0.001)$.

In the whole data set, the turbulence causes no impact on the tail spine length neither in mature nor in premature crustaceans. In the retrievals without a predator, tail spine length is considerable larger at high turbulence that at low one $(\mathrm{P}<0.001)$. When a predator is available, tail spine length in Daphnia of all ages is considerably larger at low turbulence $(\mathrm{P}<$ $0.001, \mathrm{P}<0.001$ и $\mathrm{P}<0.001$, respectively). Premature crustaceans in the whole data sets have for sure longer tail spine at low water currents velocity $(\mathrm{P}<0.001)$.

Adult and premature Daphnia in the whole data set have relatively larger helmets height at low current velocities $(\mathrm{P}<0.001)$. Under the conditions without a predator, the turbulence does not influence relative helmet height. With a predator, daphnids of all ages have a considerably larger relative helmet height at low water currents velocities $(\mathrm{P}<0.001)$, the registered values of this ratio are maximal. Under the conditions without a predator, premature and juvenile crustaceans have a considerably larger relative helmet height ( $\mathrm{P}$ $<0.01$ and $\mathrm{P}<0.001$, respectively). According to all data, juvenile Daphnia have a considerably larger relative helmet height at low turbulence $(\mathrm{P}<0.001)$.

According to all data obtained and under the conditions without a predator, the crustaceans of all ages have for sure larger relative length of tail spine at higher turbulence level than at lower one $(\mathrm{P}<0.001$, $\mathrm{P}$ $<0.05$ and $\mathrm{P}<0.001)$. Under the conditions without a predator, Daphnia of all ages have a considerably larger length of tail spine at high turbulence $(\mathrm{P}<$ $0.001, \mathrm{P}<0.05$ and $\mathrm{P}<0.001$, respectively). Under the conditions with a predator, the crustaceans of all ages have larger relative length of tail spine at low water current velocities $(\mathrm{P}<0.001, \mathrm{P}<0.05$ and $\mathrm{P}<$ 0.001 , respectively).

The results obtained showed that adult crustaceans have longer bodies at high turbulence and when a predator is available. At high current velocities, mature and juvenile crustaceans have very enlarged tail spine promoting swimming direction. At a predator presence, better developed helmets and longer tail spine are observed at low turbulence level compared to conditions without a predator. At predator presence and high turbulence, development of cyclomorphic traits is considerably better expressed than under the conditions without a predator, and variations of body proportions by helmet height are clearly observed. Combined impact of predation and turbulence onto helmet development was noticed for $D$. cucullata (Tollrian and Laforsh, 2006).

In Lake Baikal, turbulence influences the same features as predation, but less, extent the length of the body and the height of the helmet; mainly it concerns tail spine length. With a predator, the helmet height is exposed to maximal variations. Besides, interaction of environmental conditions can result both increase of effect and to its decrease. Therefore, it is difficult to pursue such variations in an environment with nonconstant parameters. Under different conditions (food and temperature), strategies for adaptation to predator and turbulence differ.

\section{References}

Baranyai E., G.-Toth L., Vari A. et al. 2011. The effect of variable turbulent intensities on the distribution of zooplankton in the shallow, large Lake Balaton (Hungary). Knowledge and Management of Aquatic Ecosystems 400: 1-13. DOI: $10.1051 / \mathrm{kmae} / 2011003$

Kiselev I.A. 1969. Plankton morey i kontinental'nykh vodoyemov. Tom 1. Vvodnyye i obshchiye voprosy planktologii [Plankton of the seas and continental water bodies. Vol. 1. Introduction and common questions of the planktology]. Leningrad: Nauka. (in Russian)

Pitul'ko S.I. 2019. Influence of food on morphological characteristics of Daphnia galeata (Cladocera, Daphniidae) from Lake Baikal. Limnology and Freshwater Biology 2: 199-204. DOI: 10.31951/2658-3518-2019-A-2-199

Tollrian R., Laforsh Ch. 2006. Linking predator kairomones and turbulence: synergetic effects and ultimate reasons for phenotypic plasticity in Daphnia cucullata. Archiv für Hydrobiologie 176: 135-146. DOI: 10.1127/0003-9136/2006/0167-0135

Shimaraev M.R., Troitskaya E.S. 2005. Seasonal features of geostrophic currents in southern Baikal. Geografiya i Prirodnyye Resursy [Geography and Natural Resources] 1: 58-65. (in Russian)

Verbolov V.I. 1977. Obshchaya kharakteristika techeniy navigatsionnogo perioda [General characteristics of navigation period currents]. In: Techeniya v Baikale [Currents in Baikal]. Novosibirsk, pp. 43-62. (in Russian) 